\title{
Common dermatology questions and answers about the radiation treatment of skin cancer in the modern era
}

\begin{abstract}
Radiotherapy (RT) for skin cancer has improved with better RT modalities and techniques. Dermatologists, especially through their support of skin cancer multidisciplinary clinics (MDCs), have asked interesting questions about radiotherapy during these clinics. To facilitate more rapid dissemination of knowledge about better RT in the modern era, dermatologists were asked in face to face interviews by a coordinator what questions they would like answered about RT in the modern era.

Over 30 dermatologists were interviewed. Common questions were: What are the clinical differences between RT, surgery and topical treatments; why does RT need to be given in so many treatments; what is the mechanism of RT at a cellular level; are RT side effects any different from side effects caused by topicals. Further questions included: are there any contraindications to RT for skin cancer; what is the minimum age to treat; are the post treatment cosmetic effects of RT better than surgery; what is the risk of second malignancy from RT; how is recurrence post RT treated; is retreatment with RT possible; can RT and surgery be combined; when should one refer for RT in perineural invasion or lymphovascular space invasion or positive margin; has RT a role in extensive disease; what RT modalities are now available and how do they differ?

Answers were devised by radiation oncologists (ROs) with a skin interest and presented at multidisciplinary educational meetings. This article is a summary of those questions and answers. Advances in RT are making RT an option for treatment of skin cancer once again. Communication between dermatologists and ROs is essential for appropriate referral.

Background: Radiotherapy (RT) for skin cancer was a common treatment used by dermatologists until the 1980s. Better surgical and topical treatments, coupled with increasing radiation regulatory requirements, led to a decline in the use of RT by dermatologists. RT modalities and techniques for skin cancer have improved but have not led to more referrals for RT from skin cancer multidisciplinary clinics (MDCs). These clinics have taken place in the Skin and Cancer Foundation and at the Kinghorn Cancer Centre in Darlinghurst Sydney. Radiation Oncologists (ROs) need to answer questions that dermatologists may have about RT.

Attending dermatologists were invited to share concerns and ask questions on current RT practice. Over 30 dermatologists were asked in face to face interviews by a coordinator what questions they would like answered about RT in the modern era. The feedback formed the basis of educational meetings. This article is a summary of those questions and answers.
\end{abstract}

Keywords: skin cancer, squamous cell carcinoma, basal cell carcinoma, radiotherapy, review
Volume 5 Issue 2 - 2018

\author{
Gerald B Fogarty, ${ }^{1,2}$ Stephen Shumack ${ }^{3}$ \\ 'Department of Radiotherapy, St Vincent's Hospital, Australia \\ 'University of Technology, Australia \\ ${ }^{3}$ Department of Dermatology, University of Sydney,Australia
}

Correspondence: Gerald B Fogarty, Department of Radiotherapy, St Vincents Hospital,Victoria St, Darlinghurst 2010 NSW, Australia, Tel +6I283025400,

Email gerald.fogarty@cancer.com.au

Received: April 03, 2018| Published: April 17, 2018
Abbreviations: RT, radiotherapy; ROs, radiation oncologists; $\mathrm{BCC}$, basal cell carcinoma; cSCC, cutaneous squamous cell carcinoma; AK, actinic keratosis; DNA, deoxyribose nucleic acid; Gy, gray; SM, second malignancy; Sx, surgery; NMSC, nonmelanoma skin cancer; RCTs, randomised controlled trials; PORT, post-operative radiotherapy; PNI, perineural invasion; SSD, sourcesurface distance; SXRT, superficial radiotherapy; BT, brachytherapy; VMAT, volumetric modulated arc therapy; IMRT, intensity modulated radiotherapy; TVMAT, tangential volumetric modulated arc therapy

\section{What is the difference between RT, surgery and topical treatments?}

Data comparing the oncological outcomes of the different modalities in these most common malignancies is regrettably inconclusive. A 2007 metanalysis $^{1}$ by the Cochrane Collaboration for basal cell carcinoma (BCC) states: "Surgery and radiotherapy appear to be the most effective treatments, with surgery showing the lowest failure rates" but concludes with "Overall there has been very little quality research on treatments for BCC." Another metanalysis ${ }^{2}$ by 
the Cochrane Collaboration for cutaneous squamous cell carcinoma (cSCC) states "little evidence from randomised controlled trials (RCTs) comparing the efficacy of different interventions for primary cutaneous SCCs exists." A further metanalysis ${ }^{3}$ by the Cochrane Collaboration for actinic keratosis (AK) does not even mention radiotherapy, for which it is effective. The data on functional and cosmetic outcomes are also only short term ${ }^{1}$. All these studies suggest there is a clear need for more robust trials with longer follow-up in skin cancer, which will only be achieved with multidisciplinary cooperation.

A major difference is that surgery does result in normal tissue loss. Surgical excision is usually a single therapeutic episode and removes an invasive cancer and surrounding normal tissue, a histopathology report then confirms the histology of the lesion and completeness of excision. RT can treat a mixed population of tumour and normal tissue, killing the tumour without normal tissue loss, thereby effecting tissue conservation (Figure 1). A number of mechanisms are at work here. ${ }^{4}$ The main difference is in deoxyribose nucleic acid (DNA) repair. Normal cells have excellent DNA repair capacity, tumour cells do not. This difference is exploited in RT. RT can therefore treat a larger, more cosmetically sensitive field than surgery because no tissue is removed (Table 1).
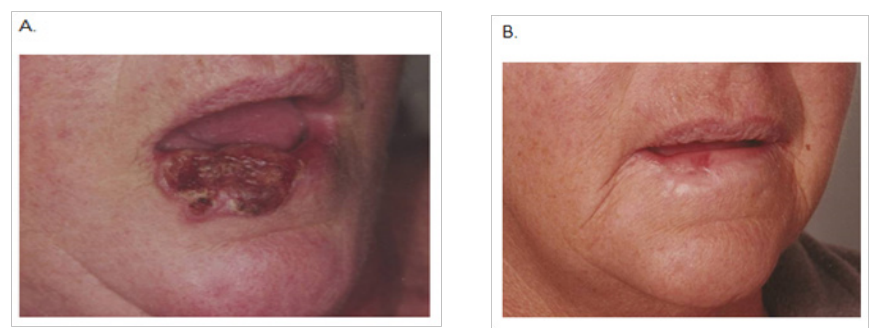

Figure I Photographs of a patient with a large $\mathrm{SSCC}$ of right lower lip treated with RT alone, demonstrating tissue conservation. A. At presentation. B: Six months following RT.

Table I Comparison of the differences between RT, surgery and topical treatments

\begin{tabular}{lllll}
\hline Modality & $\begin{array}{l}\text { Treatment } \\
\text { episodes }\end{array}$ & $\begin{array}{l}\text { Visits } \\
\text { to } \\
\text { clinic }\end{array}$ & $\begin{array}{l}\text { Histological } \\
\text { Confirmation } \\
\text { of removal }\end{array}$ & Compliance \\
\hline $\begin{array}{l}\text { Definitive } \\
\text { radiotherapy }\end{array}$ & Many & Many & No & High \\
Surgery & one & Few & Yes & High \\
Topicals & Many & Few & No & Risk of low \\
\hline
\end{tabular}

Why does radiotherapy need to be given in so many treatments?

RT is prescribed in units called Gray (Gy). ${ }^{5}$ Gy is defined as the absorption of one joule of radiation energy per kilogram of matter. Standard dosage or fractionation is to give $2 \mathrm{~Gy}$ per day, and a typical prescription is $60 \mathrm{~Gy}$ in 30 fractions at five fractions per week summarised as $60 / 30 / 5$. RT is prescribed to a defined dose point, often skin surface in skin RT. Different fractionation patterns can be compared using a special formula and a common selection is summarised in Table 2.

Normal tissue repair is completed within hours following radiotherapy. Splitting the total dose into smaller doses or fractions maximises normal tissue survival leading to minimal impact on function and cosmesis. Too much dose per treatment episode or fraction can result in overwhelming of the normal cell repair capacity. Normal cells can then die, leading to replacement with fibrosis in the long term. Late radiation side effects can develop. These are defined as starting at least six months after RT. These include all the hallmarks of fibrosis, including hypopigmentation, telangiectasia and cicatrisation (Figure 2). ROs are loath to use a smaller number of treatments, or "hypofractionate" for this reason. The more fractions, however, means several visits to the Department which can be enough for a patient with mobility issues to prefer another option, like a topical treatment or surgery. RT does not generate a histopathology report, similarly with topical treatment. Topicals are more convenient as administered by the patient at home but there can be issues of compliance and complete coverage of the field that needs to be treated, leading to a risk of marginal recurrence. ${ }^{6}$

Table 2 Summary of a selection of different fractionation patterns that give comparably the same oncological outcomes. Higher dose per fraction means less clinic visits but will give a worse functional and cosmetic result

\begin{tabular}{lll}
\hline Total dose (Gy) & $\begin{array}{l}\text { No of } \\
\text { fractions } \\
\text { /weeks of RT }\end{array}$ & Dose per fraction \\
\hline 60 & $30 / 6$ & 2 \\
55 & $25 / 5$ & 2.25 \\
50 & $20 / 4$ & 2.5 \\
45 & $15 / 3$ & 3 \\
40 & $10 / 2$ & 4 \\
36 & $6 / 2$ & 6 \\
\hline
\end{tabular}
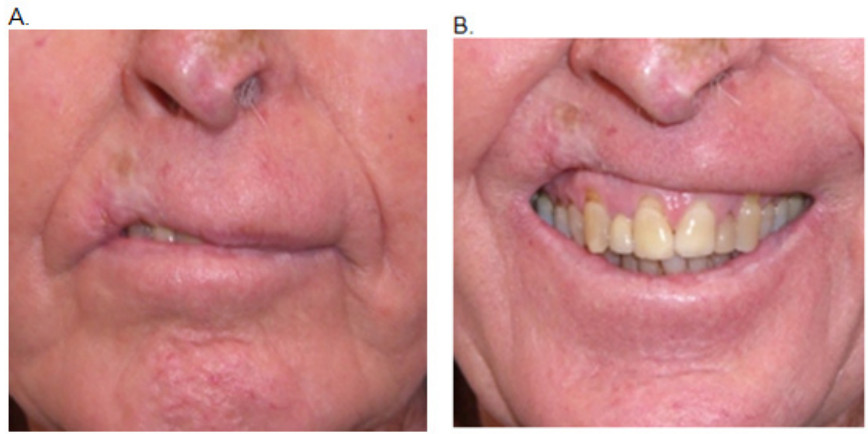

Figure 2 (A) cSCC lip treated years ago with hypofractionation leading to telangiectasia, cicatrisation, atrophy and hypopigmentation; $\mathrm{B}$ :Hypofractionation has had a deleterious functional and cosmetic effect.

\section{What is the mechanism of RT at a cellular} level?

RT causes double stranded breaks in DNA. Recombination results in nonsense chromosomes incompatible with further cell division. Cells cannot divide, and will eventually die.

\section{Are RT side effects any different from side effects caused by topicals?}

Side effects in normal tissues are best avoided by not treating normal tissue, and so the technological drive in RT has resulted in greater dose "conformality", that is, more dose to cancer, less dose to 
normal tissues. There is always however, some normal tissue in the irradiated volume that requires fractionation to conserve.

RT side effects can be considered as either acute or late. Acute effects happen during and immediately after treatment and are a sterile acute inflammation in select normal tissue. These select normal tissues have a similar life cycle to cancer and include gut, mucosa, bone marrow and skin. They have a hierarchal distribution. Stem cells with a rich blood supply make new cells that migrate, eg in skin, keratinocytes are pushed away from the blood supply in the dermis by ever new cells, and eventually die and are sloughed off as keratin. This process takes from 1-2 weeks depending on body site. RT stops normal cell division today so that in 1-2 weeks skin cells that should be protecting the stem cells are absent. They have never been made as the stem cells were busy protecting their DNA during the time of RT.

The peak skin radiation side effect may happen after treatment is completed, depending on how accelerated the treatment has been. In skin, the usual acute inflammation hall marks are initially erythema, then dry desquamation, then wet desquamation as the number of fractions increases and the amount of dose accumulates. Specialist nursing care is needed to prevent infection through this open skin, and patients have appropriate topical treatments administered by radiation nurses who regularly review patients on treatment. This acute inflammation process is shown in the case study in Figure 3.

A.

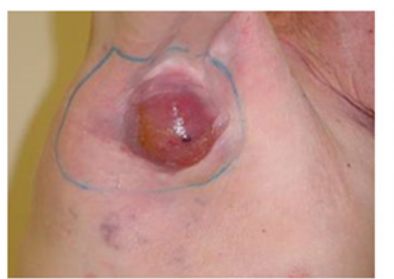

C.

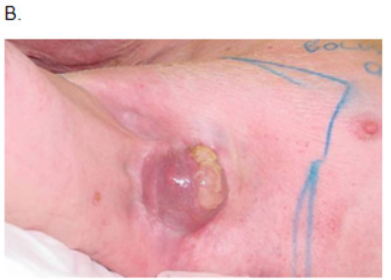

D.
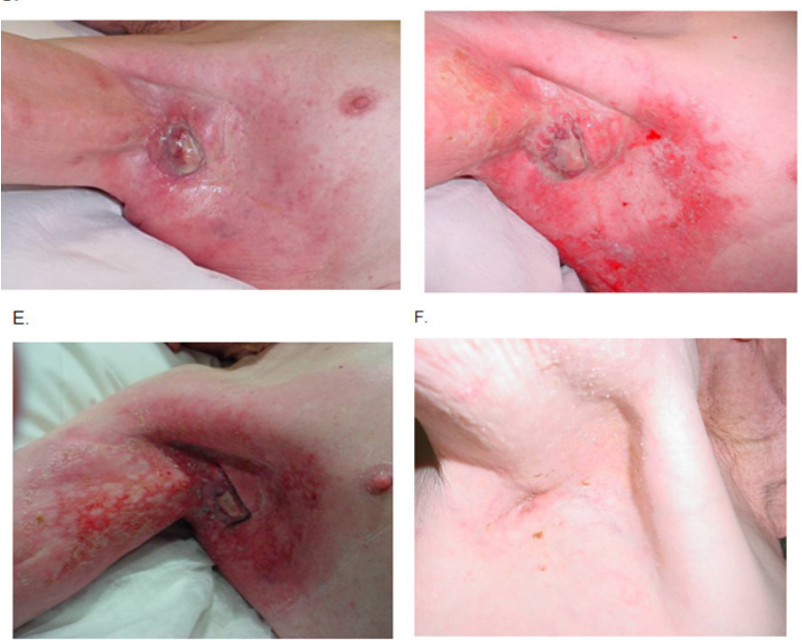

Figure 3 (A) Inoperable metastatic CSCC to axilla treated with definitive RT alone. Dose prescribed is 45Gy in 15 fractions at 5 per week $(45 / 15 / 5)$ with full dose to normal skin. B: At 27Gy, RT field outlined in blue chinagraph, no skin reaction yet. Yellow material on tumour is tumorlysis or necrosis, not pus. C: At 7 days post RT, erythema is present in field. D: At 14 days post RT, wet desquamation is present in field, the peak of the RT reaction. This is not cellulitis, as the reaction is only in field. At this stage there is a need for careful skin care as the skin is open. There is no need for antibiotics. E: 21 days, recovery is progressing with formation of islands of new skin from surviving skin stem cells. F: 120 days - Skin fully healed and a complete response for the cancer.
RT late effects begin at six months post RT and are the result of normal cell death during therapy. This normal cell death is usually caused by large doses per fraction, when normal cells die and are eventually replaced by fibrous tissue. This is a sterile chronic inflammation dominated by fibrosis with all the classic hallmarks of poor RT: hypopigmentation, telangiectasia and cicatrisation (Figure 2). Late effects do not get better and justify fractionation.

\section{Are there any contraindications to RT for skin cancer?}

Absolute contraindications are rare and include those with DNA repair problems for example xeroderma pigmentosum, trichothiodystrophy and Gorlin's syndrome. Concerns about internal scatter make RT contraindicted in pregnant women. Relative contraindications include those with connective tissue diseases and where questionable blood supply can influence wound healing particularly lower limb arteriosclerosis, varicose veins, diabetes etc. These cases are best decided with colleagues in a multidisciplinary forum, as RT may be the only option left for cure.

\section{What is the minimum age to treat?}

There is no data to support an age cut-off. Some skin cancer physicians say that RT should be reserved for the over $60 \mathrm{~s}$. This is driven by a supposition that RT causes poor cosmesis and older folk are not as concerned about this. This is not true in the modern era. Another concern is second malignancy. So this question can also be rephrased as 2 questions, firstly about late cosmetic effects and then about the risk of second malignancy. A reasonable cut off is 40 when there are other treatment options and the rationale is explained below.

\section{Are the post treatment cosmetic effects of RT better than surgery?}

There is no level one data comparing cosmetic outcomes with modern RT versus surgery in skin cancer. The traditional teaching is that with time surgical scars get better, and radiation fields get worse. This is from the days when RT was given in a hypofractionated manner and is not the case when RT is adequately fractionated.

\section{What is the risk of second malignancy from RT?}

Second malignancy (SM) data will never be of level one evidence. It is not ethical to randomise patients to a no-treatment arm just to test for SM. The existing data is all retrospective and open to selection bias. For ROs, there is some good news as SM only occurs in survivors. Anecdotally SM in skin cancer is rare. Senior Australian dermatologists with extensive experience in skin RT have said they have never seen a SM from RT (Rob Sinclair, Rod Paver; personal communications).

One factor in favour of skin RT is the volume effect: the volume irradiated in skin cancer is only skin deep, and so easy to follow, unlike the large volumes of normal tissue irradiated when deeper tumours, eg prostate cancer, are irradiated (Figure 4). A study that sheds light on this problem is in a benign condition. Shore el al. ${ }^{7}$ compared 2200 children who received X-ray treatment for ringworm of the scalp to a comparable group of 1400 treated without $\mathrm{X}$ ray followed for a median of 26 years since treatment. They found in the irradiated group, 41 had one or more basal cell carcinomas of the scalp or face 
while only three have been diagnosed in the control group. There was a high prevalence of multiple skin cancers in the irradiated group (80 lesions among 41 cases). The minimum latent period for radiationinduced skin cancers was long-about 20 years. The skin cancer risk was particularly pronounced on the face, where there would be more ultra violet exposure in addition to X-ray exposure. Skin cancers were found only among caucasians, even though $25 \%$ of the study population were afro-americans. A literature review was undertaken of second primary neoplasms (SPNs) following RT in cancer patients and is tabulated in Table $3 .^{8-11}$

Table 3 RT in cancer patients

\begin{tabular}{|c|c|c|c|c|c|c|}
\hline Study & $\begin{array}{l}\text { Year of } \\
\text { pub }\end{array}$ & Study & Question asked & Findings I & Findings 2 & Findings 3 \\
\hline Oeffinger ${ }^{8}$ & 2013 & Review & SM post treatment & $8 \%$ due to RT & $\begin{array}{l}\text { RT }<30 \text { yrs at } \\
\text { incr risk }\end{array}$ & $\begin{array}{l}\text { long latency } \\
\text { period }\end{array}$ \\
\hline Hegemann ${ }^{9}$ & 2017 & $\begin{array}{l}\text { RT v Sx/RT v Sx in } \\
20,000 \text { men }\end{array}$ & $\begin{array}{l}\text { SM post RT for } \\
\text { prostate cancer }\end{array}$ & $\begin{array}{l}\text { I0 yr incidence SM: } \\
\text { RT I } 5.9 \% \text {; } \\
\text { Sx/RT I3.2\%; Sx } \\
\text { I0.5\%. }\end{array}$ & $\begin{array}{l}\text { No increase } \\
\text { due to RT }\end{array}$ & \\
\hline Braam $^{10}$ & 2012 & Systematic review & $\begin{array}{l}\text { Malignant melanoma } \\
\text { as SM in childhood } \\
\text { cancer survivors }\end{array}$ & $\begin{array}{l}\text { I5I,575 pts; } \\
4,010(2.6 \%) \text { had SM; } \\
212(0.14 \%) \text { were } \\
\text { melanoma }\end{array}$ & $\begin{array}{l}\text { Incr risk if } \\
\text { RT combined } \\
\text { with chemo }\end{array}$ & \\
\hline Daniëls"l & 2013 & Retrospective & $\begin{array}{l}\text { SM after RT in } \\
\text { Hodgkins }\end{array}$ & $\begin{array}{l}\text { 86/889 developed } 318 \\
\text { skin } C a \text {, usually } B C C\end{array}$ & $\begin{array}{l}\text { Incr freq if } \\
<35 y r s \text { at RT }\end{array}$ & $\begin{array}{l}\text { long latency } \\
\text { period }\end{array}$ \\
\hline
\end{tabular}

A reasonable way forward, based on these large studies, is that the risk of SM post RT is approximately 1 in 1,000 at 10 years. Giving RT has to be balanced against the risk of cancer recurrence if no RT is given. If the risk of recurrence is $30 \%$ of recurrence within a few years, then the small risk of SM from RT is justified. This risk level of $30 \%$ is used in other tumour types to justify adjuvant radiotherapy eg breast cancer. ${ }^{12}$ The evidence for and against irradiating below 40 years of age is of low quality. Care should be taken with irradiating the young as they have a longer life span to exhibit a SM, and should be done with the consensus of a multidisciplinary team decision.

A.

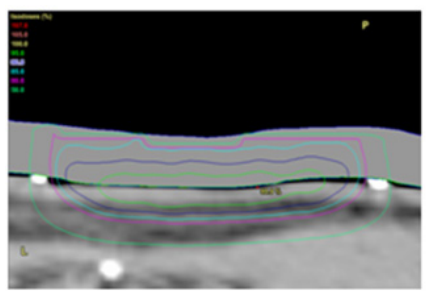

B.

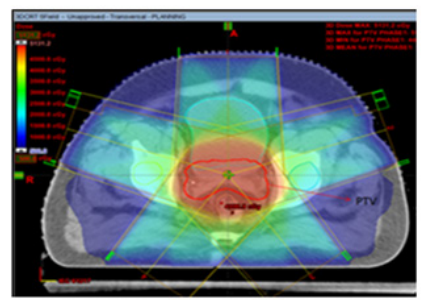

Figure 4 (A) RT Dosimetry for skin cancer B: RT dosimetry for prostate cancer. Note difference in normal tissue in irradiated volume.

\section{In favour of decreased morbidity from SM from skin RT is:}

a. Skin cancer patients after RT will be followed up and so a SM can be seen and treated immediately.

b. Modern RT modalities and techniques ensure that the volume of in-field normal tissue is minimised.

\section{How is recurrence post RT treated?}

Recurrent cancer after RT usually means that either the tumour is radioresistant or RT has been of inferior quality. We have no test yet to determine individual lesion radiosensitivity, and research is needed. Recurrence as the result of inferior quality RT is more common. RT quality can be decreased because of inappropriate dose or volume.
The latter is more common. Most definitive skin RT planning consists of visual inspection of the lesion and marking of a field on skin. Poor lighting and lack of attention to detail can result in poor planning and field placement, leading to inferior dosimetry at the margin of the lesion, resulting in a marginal recurrence over time. Recurrence may be re-treated with RT by adding on an abutting field, but there will be significant overlap. Long fractionation to avoid late effects in the junction zone will be needed.

Infield recurrence can be due to inadequate depth of treatment. Beams that do not penetrate to cover the depth of the skin appendages should not be used. The deepest skin appendage in a group of patients with lentigo maligna was found to be $4.5 \mathrm{~mm}^{13}$ (Figure 5). Therefore, conservatively the treatment depth needs to be $5 \mathrm{~mm}$ within the field. Grenz rays, a very low penetrating RT, have been associated with significant in field recurrences ${ }^{13,14}$ (Figure 6). Salvage treatment with surgery or another modality is needed. Care needs to be taken as surgical healing post RT can be difficult and dehiscence leading to radio-necrotic ulcers and fistula can occur. An experienced surgeon in post RT recurrence is of benefit and they may decide to remove the entire previous RT field with a more complex repair to avoid these problems. The previous field can be traced on by the radiation staff to aid excision. ${ }^{15}$

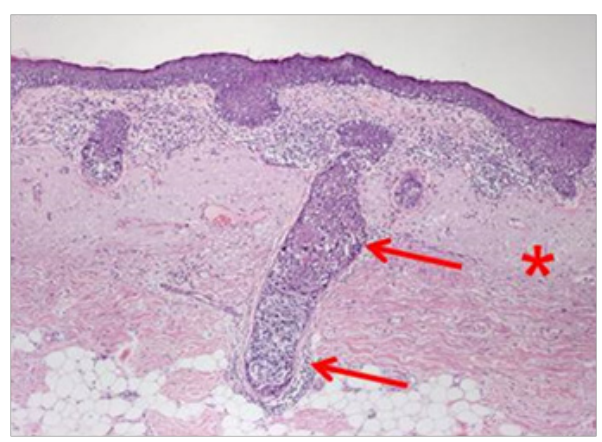

Figure 5 In situ cancers involving the depths of hair follicles which can be up to $4.5 \mathrm{~mm}$ in depth. 


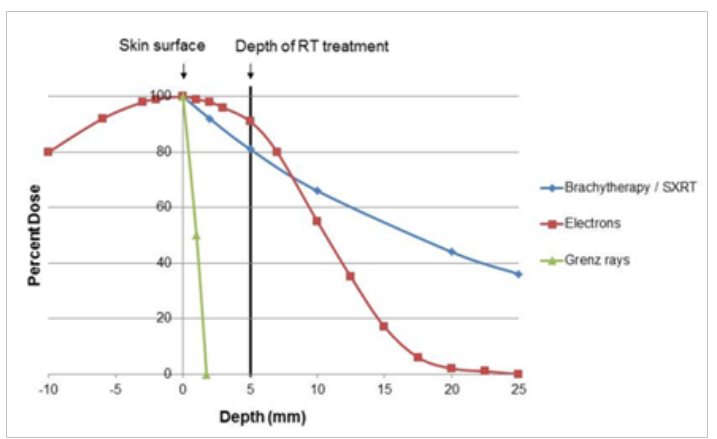

Figure 6 Only beams that treat to sufficient depth should be used. Grenz rays have inadequate penetration and are associated with in-field failure.

\section{Is retreatment with $\mathbf{R T}$ possible?}

Many factors need to be assessed in this scenario. RT dose is "forgotten" by in-field normal tissue in important late-reacting doselimiting organs at a rate of $50 \%$ each year. ${ }^{16}$ Clinical judgement of RT side effects in the previously treated field such as telangiectasia, cicatrisation, atrophy and hypopigmentation help to assess whether the tissue in question can sustain another radical course. Re-treatment runs the risk of tissue breakdown resulting in the possibility of difficult lesions such as with radio necrotic ulcers and fistula. Another treatment modality is preferred but usually comes down to a multidisciplinary decision. There may be no other option than RT.

Marginal recurrence may be retreated as the dose to the normal tissue has not been too high. Adding on an abutting RT field may involve significant overlap and standard fractionation may be needed to avoid late effects in the junctional area. It is now possible to treat whole fields of skin cancerisation so this may be done up front to avoid having to add on abutting fields in the future. ${ }^{17}$

\section{Can RT and surgery be combined?}

RT is combined with surgery in other malignancies eg sarcoma ${ }^{18}$ to achieve limb conservation, rectum ${ }^{19}$ to achieve better quality of life with removal of irradiated bowel, and breast ${ }^{20}$ to achieve operability. Planned surgery is done in the window between resolution of acute effects and beginning of late effects, usually 4-12 weeks following RT. All outcomes are met, but there can be a tendency to more wound complications with neoadjuvant RT.

Planned combination is usually not warranted considering that both modalities give excellent local control for most small nonmelanoma skin cancer (NMSC). ${ }^{21}$ RCTs are few compared to the problem. A Canadian RCT, that of Avril et al. ${ }^{22}$ compared surgery with RT and allowed four types of radiotherapy. Clearance at 4 years of 173 in the RT arm was $92.5 \%$ compared with 174 in the surgery arm of $99 \%$. Combination usually occurs in an unplanned manner when the post-surgical histopathology shows adverse features ${ }^{23}$ requiring post-operative RT (PORT) or there is biopsy proven recurrence post RT requiring salvage surgery. There is little level one data of planned combination except in the scenario of adjuvant RT following surgery for $\mathrm{cSCC}$ metastatic to parotid which shows the combination has excellent local control even without chemotherapy. ${ }^{24}$

Skin surgeons need to be aware of the concept of overall treatment time. Delaying referral for PORT for positive margin to ensure completion wound healing of a complex closure can compromise cure. ${ }^{25}$ RT should start within four weeks and not more than six post operation. The closure will continue to heal even during the initial RT. Operating through irradiated tissue suffering late effects is difficult. The usual healing mechanism especially caused by radiationinduced arteriosclerosis may be absent and significant side effects like dehiscence, radionecrotic ulcer and fistula can result. Discussion with the prescribing RO is advised prior to salvage surgery. Particular scenarios are perineural invasion (PNI) and lymphovascular space invasion (LVSI). Whether PNI is associated with lymph node positivity in cSCC is controversial. ${ }^{26,27}$ There are no prospective trials in these scenarios.

\section{When should one refer for PORT in PNI?}

An excellent recent review on PNI is Karia et al..$^{28}$ on PORT in PNI is Han et al. ${ }^{29}$ A reasonable working model is based on these three scenarios. Incidental PNI is when there have been no symptoms of PNI and PNI is reported on the histopathology form. Skip metastases are just contiguous spread. ${ }^{30}$

a. Incidental intratumoral PNI of small nerves in a lesion less than $2 \mathrm{~cm}$ with adequate margins $(4 \mathrm{~mm})$ does not need referral but close clinical monitoring. Immunosuppressed patients and patients with tight margins require greater vigilance.

b. Incidental extratumoral PNI usually occurs at the deep margin. If this is close (eg $<2 \mathrm{~mm}$ ) then consider referral especially if there are other relative factors for recurrence eg recurrent lesion, lesion over $4 \mathrm{~mm}$ thick, over $2 \mathrm{~cm}$ in diameter, involvement of largercalibre nerves and tumour invasion beyond dermis. ${ }^{31}$

c. Clinical PNI means that at presentation PNI symptoms or signs are present. These symptoms are often missed and must be enquired about eg formication, motor loss and/or paraesthesia in the nerve distribution. The patient may not associate the symptoms with the lesion. These lesions need a timely multidisciplinary approach. In the head and neck they often need significant investigation, surgery and PORT. Mortality is a real possibility. ${ }^{32}$

\section{When should one refer for PORT in lymphovascular space invasion (LVSI)?}

Retrospective data ${ }^{27}$ in cSCC cancer shows a small risk (less than $2 \%$ ) if this is the only risk factor. Referral can be based on risk presence of other poor prognosis factors such as immunosuppression, recurrent disease, tumour size, PNI, poor histological differentiation, margin status, location in the ear, cheek, lip and retro-auricular areas. Single institution retrospective data ${ }^{33}$ shows that high-risk patients treated with elective nodal RT to $50 \mathrm{~Gy}$ had $96 \%$ in field control at 4.5 years median follow up. Whether to initially treat the primary site alone or include first echelon nodes is an area ripe for research.

\section{Has $\mathbf{R T}$ a role in incompletely excised disease?}

Common referrals for RT are NMSC excised with positive margin in patients in which further surgery is either declined or too morbid. Once again recent data is of inferior quality. Lara et al. ${ }^{34}$ report that in a single institution retrospective study made up of 487 patients treated with surgery alone for $\mathrm{CSCC}$, there was a rate of positive margins after surgery of $12.18 \%$. There were five cases of tumoral recurrence in the observation group and three cases in the re-excision group. 
This suggests not all positive cSCC margins recur and that further treatment does not stop recurrence. Factors such as tumour size, site, histological type, ulceration and type of positive margin were not significant in predicting recurrence rates in this study. ROs will treat positive margins. RT post-surgery is safe if done with experience. RT can also even be a definitive treatment for skin cancer. ${ }^{21}$

\section{Has $\mathbf{R T}$ a role in extensive disease?}

External beam RT (EBRT) for skin cancer has recently been revolutionised by the adoption of volumetric modulated arc therapy (VMAT), which is the newest stage in the evolution of intensity modulated RT (IMRT). ${ }^{35}$ Tangential VMAT (TVMAT) is ideal for scalps. ${ }^{17}$ VMAT is essentially the application of computed tomography technology to RT and can treat large fields of skin quickly and accurately with great conformality that is without overdosing surrounding dose-sensitive normal tissues. RT for specific patients is limited by the modalities and techniques available in any given department.

\section{What RT modalities are available and how do they differ?}

Modalities that can treat skin cancers include brachytherapy (BT) and EBRT. EBRT involves radiation created outside the patient and beamed into the target from a source relatively distant from it. Brachytherapy (BT) involves the use of radioactive sources that are laid onto or into the target. BT in the treatment of skin field cancerisation is delivered via a specially constructed surface mould (Figure 7). The homogeneity of the surface dose depends on the distance of the sources from each other, and the distance of the skin to the sources (called "standoff"). Surface moulds contain catheters along which a high dose rate source travels under computer control. The energy of the photons emitted from the source and the source standoff distance will also determine the dose at depth in the skin. BT mould construction requires a dedicated trained team. Mould application at treatment must be exact to deliver the prescribed dose. VMAT, a type of EBRT, is replacing BT. ${ }^{17}$

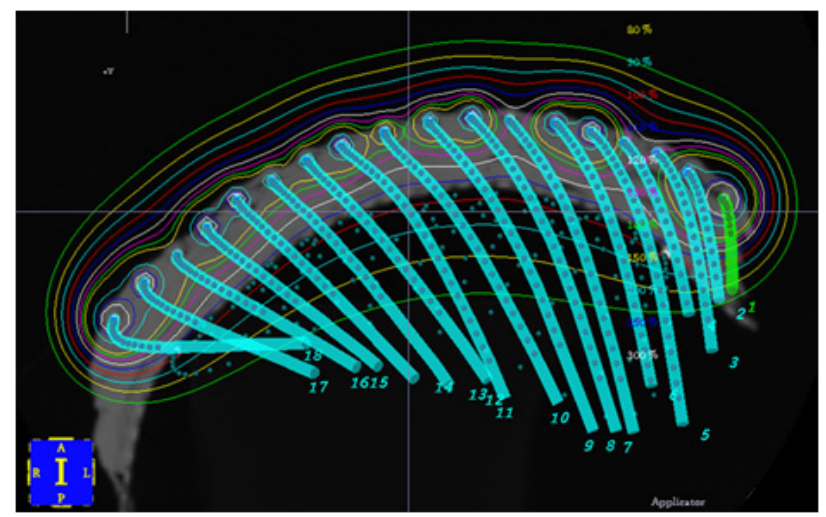

Figure 7 A computer representation of a brachytherapy mould plan where the brachytherapy catheters are kept in a pattern by the mould, usually separated by equal spacing. The mould is made of a water-equivalent material called bolus or build up. Bolus between the brachytherapy catheters and the skin attenuates the radiation. This enables the dose cloud, by the time it gets to the skin, to have a homogeneous wave front. See the thin red line that would hug the skull $5 \mathrm{mms}$ under the mould.

EBRT can deliver photons, electrons or protons. Electronic brachytherapy is a type of EBRT but with a short source - surface distance (SSD), less than $10 \mathrm{~cm}$. It therefore can only treat a small area. Superficial RT (SXRT) has a longer SSD and can treat to a larger field (usually up to $8 \mathrm{~cm}$ diameter) depending on the machine and with more homogenous dose at depth. These modalities are excellent for areas that are concave to the beam profile eg inner canthus.

Larger fields can be treated with megavoltage electrons up to $20 \mathrm{~cm}$ squared. Electrons have several disadvantages. A layer of tissueequivalent material called bolus is needed to bring the maximum dose onto the skin which increases the set-up time and the uncertainty of treatment. Electron beams have a wide penumbra and so more normal tissue will be irradiated. Flat fields are preferred for better dosimetry. The skin that is to be treated can be modified to make it flat (Figure 8). One can also use bolus material to make the field as flat as possible, for example, filling a conchal bowl. Megavoltage photons via VMAT can even treat large fields surfaces of skin field cancerisation that are convex to the incident beam. These anatomical areas include the scalp, forehead, cheeks, forearms, legs, chest upper back, and shoulders. This is an area of active research.

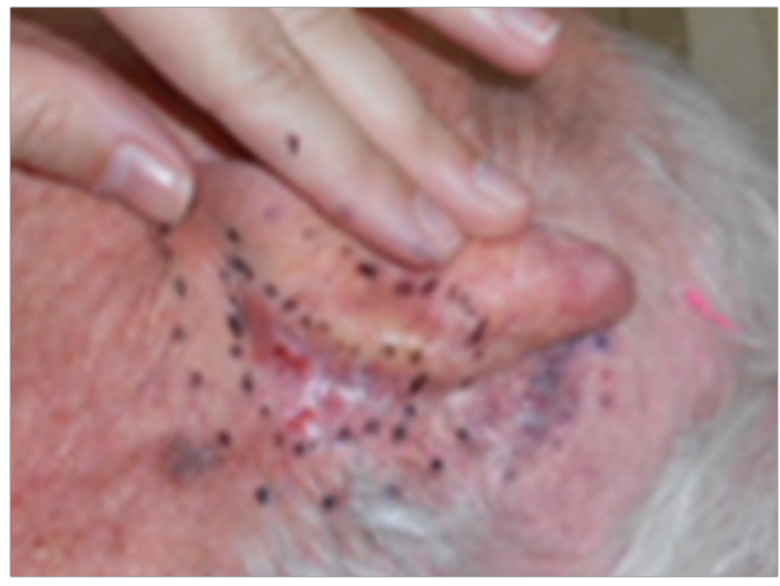

Figure 8 Electron beam dosimetry is more reliable with a flat field. The skin can be modified to make the surface flat. For example, one can tape the ears forward to treat the posteromedial surface of the pinna as in the figure. Note the inner dotted area which denotes tumour and the outer dotted area denotes the field, which needs to be larger for electron beams than for SXRT as the beam penumbra is wider.

\section{Conclusion}

Improvements in RT are making it an option for treatment of skin cancer once again. Communication between dermatologists and ROs is essential for appropriate referral. ROs need to inform doctors who look after skin cancer what is now available. Multidisciplinary educational meetings have aided this process. Continued collaboration between dermatology and ROs can lead to high levels of research in RT for skin cancer that will hopefully result in better patient care.

\section{Authors' contributions}

Gerald B Fogarty: Did literature reviews and articulated answers to questions and wrote manuscript.

Stephen Shumack: Provided access to dermatologists and read and approved final document.

\section{Acknowledgements}

We would like to thank all the dermatologists who agreed to be interviewed and who attended the educational evenings. We would 
also like to thank Michelle Jobbins of Genesis Cancer Care for organising the interview logistics and the educational events so well.

\section{Conflict of interest}

The author declares there is no conflict of interest.

\section{References}

1. Bath-Hextall FJ, Perkins W, Bong J, et al. Interventions for basal cell carcinoma of the skin. Cochrane Database Syst Rev. 2007;24(1):CD003412.

2. Lansbury L, Leonardi-Bee J, Perkins W, et al. Interventions for non-metastatic squamous cell carcinoma of the skin. BMJ. 2010;14(4):CD007869.

3. Gupta AK, Paquet M. Network meta-analysis of the outcome 'participant complete clearance' in non-immunosuppressed participants of eight interventions for actinic keratosis: a follow-up on a Cochrane review. Br J Dermatol. 2013;169(2):250-259.

4. Marcu LG. The first Rs of radiotherapy: or standing on the shoulders of giants. Australas Phys Eng Sci Med. 2015;38(4):531-541.

5. Bureau International des Poids et Mesures (BIPM). The International System of Units. 2018.

6. Philipp-Dormston WG. Field cancerization: from molecular basis to selective field-directed management of actinic keratosis. Curr Probl Dermatol. 2015;46:115-21.

7. Shore RE, Albert RE, Reed M, et al. Skin cancer incidence among children irradiated for ringworm of the scalp. Radiat Res. 1984;100(1):192-204.

8. Oeffinger KC, Baxi SS, Novetsky Friedman D, et al. Solid tumor second primary neoplasms: who is at risk, what can we do? Semin Oncol. 2013;40(6):676-689.

9. Hegemann NS, Schlesinger-Raab A, Ganswindt U, et al. Risk of second cancer following radiotherapy for prostate cancer: a population-based analysis. Radiat Oncol. 2017;12(1):2.

10. Braam KI, Overbeek A, Kaspers GJ, et al. Malignant melanoma as second malignant neoplasm in long-term childhood cancer survivors: a systematic review. Pediatr Blood Cancer. 2012;58(5):665-674.

11. Daniëls LA, Krol AD, Schaapveld M, et al. Long-term risk of secondary skin cancers after radiation therapy for Hodgkin's lymphoma. Radiother Oncol. 2013;109(1):140-145.

12. Overgaard M, Nielsen HM, Overgaard J. Is the benefit of postmastectomy irradiation limited to patients with four or more positive nodes, as recommended in international consensus reports? A subgroup analysis of the DBCG 82 b\&c randomized trials. Radiother Oncol. 2007;82(3):247253

13. Fogarty GB, Hong A, Scolyer RA, et al. Radiotherapy for lentigo maligna a literature review and recommendations for treatment. $\mathrm{Br} J$ Dermatol. 2014;170(1):52-58.

14. Petratos MA, Kopf AW, Bart RS, et al. Treatment of melanotic freckle with X-rays. Arch Dermatol. 1972;106(2):189-194.

15. Kopf AW, Bart RS, Gladstein AH. Treatment of melanotic freckle with $\mathrm{x}-$ rays. Arch Dermatol. 1976;112(6):801-807.

16. Ang KK, Jiang GL, Feng Y, Stephens LC, et al. Extent and kinetics of recovery of occult spinal cord injury. Int J Radiat Oncol Biol Phys. 2001;50(4):1013-1020.

17. Santos ED, Green JA, Bhandari N, et al. Tangential Volumetric Modulated Radiotherapy - A New Technique for Large Scalp Lesions with a Case Study in Lentigo Maligna. Int J Bioautomation. 2015;19(2):223-236.

18. O'Sullivan B, Davis AM, Turcotte R, et al. Preoperative versus postoperative radiotherapy in soft-tissue sarcoma of the limbs: a randomised trial. Lancet. 2002;359(9325):2235-2241.

19. Erlandsson J, Holm T, Pettersson D et al. Optimal fractionation of preoperative radiotherapy and timing to surgery for rectal cancer (Stockholm III): a multicentre, randomised, non-blinded, phase 3, noninferiority trial. Lancet Oncol. 2017;18(3):336-346.

20. Riet FG, Fayard F, Arriagada R, et al. Preoperative radiotherapy in breast cancer patients: 32 years of follow-up. Eur J Cancer. 2017;76:45-51.

21. Ashby MA, Smith J, Ainslie J, et al. Treatment of nonmelanoma skin cancer at a large Australian center. Cancer. 1989;63(9):1863-1871.

22. Avril MF, Auperin A, Margulis A, et al. Basal cell carcinoma of the face: surgery or radiotherapy? Results of a randomized study. $\mathrm{Br} J$ Cancer. 1997;76(1):100-106

23. Porceddu SV. Prognostic factors and the role of adjuvant radiation therapy in non-melanoma skin cancer of the head and neck. Am Soc Clin Oncol Educ Book. 2015:e513-e518.

24. Porceddu Sandro Virgilio, Michael Poulsen, Mathias Bressel, et al Post-operative concurrent chemo-radiotherapy versus post-operative radiotherapy in high-risk cutaneous squamous cell carcinoma of the head and neck: A randomized phase III trial (Trans-Tasman Radiation Oncology Group 05.01 Trial; POST study). Journal of Clinical Oncology. 2017;35(15):6008-6008.

25. GB Fogarty, J Burt, J Ainslie. Delay of post-operative radiotherapy in high risk skin cancer can be associated with recurrence. J Plast Reconstr Aesthet Surg. 2006;59(2):203-205.

26. Warren TA, Whiteman DC, Porceddu SV, et al. Insight into the epidemiology of cutaneous squamous cell carcinoma with perineural spread. Head Neck. 2016;38(9):1416-1420.

27. Brougham ND, Dennett ER, Cameron R, et al. The incidence of metastasis from cutaneous squamous cell carcinoma and the impact of its risk factors. J Surg Oncol. 2012;106(7):811-815.

28. Karia PS, Morgan FC, Ruiz ES, et al. Clinical and Incidental Perineural Nerve Invasion of Cutaneous Squamous Cell Carcinoma: A Systematic Review and Pooled Analysis of Outcome Data. JAMA Dermatol. 2017;153(8):781-788

29. Han A, Ratner D. What is the role of adjuvant radiotherapy in the treatment of cutaneous squamous cell carcinoma with perineural invasion? Cancer. 2007;109(6):1053-1059.

30. Panizza B, Warren TA, Solares CA, et al. Histopathological features of clinical perineural invasion of cutaneous squamous cell carcinoma of the head and neck and the potential implications for treatment. Head Neck. 2014;36(11):1611-1618.

31. Gupta A, Veness M, De'Ambrosis B, et al. Management of squamous cell and basal cell carcinomas of the head and neck with perineural invasion. Australas J Dermatol. 2016;57(1):3-13.

32. Solares CA, Lee K, Parmar P, et al. Epidemiology of clinical perineura invasion in cutaneous squamous cell carcinoma of the head and neck. Otolaryngol Head Neck Surg. 2012;146(5):746-751.

33. Wray J, Amdur RJ, Morris CG, et al. Efficacy of elective nodal irradiation in skin squamous cell carcinoma of the face, ears, and scalp. Radiation Oncology. 2015;10:199.

34. Lara F, Santamaría JR, Garbers LEF de M. Recurrence rate of basal cell carcinoma with positive histopathological margins and related risk factors. An Bras Dermatol. 2017;92(1):58-62.

35. Fogarty G, Ng D, Liu G, et al. Volumetric modulated arc therapy is superior to conventional intensity modulated radiotherapy - a comparison among prostate cancer patients treated in an Australian centre. Radiat Oncol. $2011 ; 6: 108$. 